\title{
Dietary cadmium exposure and prostate cancer incidence: a population-based prospective cohort study
}

\author{
B Julin", , A Wolk', J-E Johansson ${ }^{2,3}$, S-O Andersson ${ }^{2,3}$, O Andrén ${ }^{2,3}$ and A Åkesson' \\ 'Unit of Nutritional Epidemiology, The Institute of Environmental Medicine, Karolinska Institutet, Box 210, 17177 Stockholm, Sweden; ${ }^{2}$ School of \\ Health and Medical Sciences, Örebro University, 70185 Örebro, Sweden; ${ }^{3}$ Department of Urology, Örebro University Hospital, 70185 Örebro, \\ Sweden
}

BACKGROUND: Experimental data convincingly propose the toxic metal cadmium as a prostate carcinogen. Cadmium is widely dispersed into the environment and, consequently, food is contaminated.

METHODS: A population-based cohort of 41089 Swedish men aged 45-79 years was followed prospectively from 1998 through 2009 to assess the association between food frequency questionnaire-based estimates of dietary cadmium exposure (at baseline, 1998) and incidence of prostate cancer (3085 cases, of which 894 were localised and 794 advanced) and through 2008 for prostate cancer mortality (326 fatal cases).

RESULTS: Mean dietary cadmium exposure was $19 \mu \mathrm{g}$ per day \pm s.d. 3.7. Multivariable-adjusted dietary cadmium exposure was positively associated with overall prostate cancer, comparing extreme tertiles; rate ratio (RR) I.I3 (95\% confidence interval (Cl): I.03-1.24). For subtypes of prostate cancer, the RR was I.29 (95\% Cl: I.08-1.53) for localised, I.05 (95\% Cl: 0.87-1.25) for advanced, and I. 14 (95\% Cl: 0.86-I.5I) for fatal cases. No statistically significant difference was observed in the multivariable-adjusted risk estimates between tumour subtypes $\left(P_{\text {heterogeneity }}=0.27\right)$. For localised prostate cancer, RR was I.55 (I.I6-2.08) among men with a small waist circumference and RR 1.45 ( I.I5, I.83) among ever smokers.

CONCLUSION: Our findings provide support that dietary cadmium exposure may have a role in prostate cancer development. British Journal of Cancer (2012) 1 07, 895-900. doi:I0.1038/bjc.2012.31 I www.bjcancer.com

Published online 31 July 2012

(c) 2012 Cancer Research UK

Keywords: dietary cadmium; epidemiology; prospective cohort; prostate cancer; subtypes

The metal cadmium is classified as a human carcinogen based on evidence for increased risk of lung cancer among occupationally exposed (IARC, 2011). Originating mainly from anthropogenic sources, cadmium is, however, also widely dispersed into the environment (Pan et al, 2010). Consequently, farmland has become contaminated and thereby food constitutes the main source of exposure in the non-smoking population (Järup and Åkesson, 2009).

Prostate cancer is the leading type of cancer among males in developed countries and the second most common worldwide (Jemal et al, 2011). Still, the causes of prostate cancer are largely unknown (Patel et al, 2008). The prostate has been shown to be a target organ for the deposition of cadmium (Elinder, 1985; Lindegaard et al, 1990; Brys et al, 1997) and several experimental studies show that cadmium can act as a prostate carcinogen, inducing tumours and hyperplastic lesions in rat prostate (Waalkes, 2003). At low doses $\left(\sim 5.0 \mu \mathrm{mol} \mathrm{Cd} \mathrm{kg}^{-1}\right)$, this induction is dose-dependent, whereas at high doses, there is no typical dose-response pattern as the proliferative response is lost (Waalkes, 2003). Intestinal uptake of cadmium appears to be influenced by micronutrients, such as Zinc (Kippler et al, 2009), and a study evaluating total prostate-specific antigen (PSA) levels in relation to urinary cadmium concentrations and dietary zinc

*Correspondence: Dr B Julin; E-mail: Bettina.Julin@ki.se

Received 6 March 2012; revised 6 June 2012; accepted I8 June 2012; published online 31 July 2012 intake provided suggestive evidence for an interaction $(P=0.09)$ between zinc intake and cadmium exposure (van Wijngaarden et al, 2008). Some earlier epidemiological studies have observed an association between cadmium and prostate cancer among occupationally exposed men, whereas more recent and larger studies did not confirm those findings (Sahmoun et al, 2005; IARC, 2011). Whether such an association exists also in environmentally exposed subjects remains unknown and results from case-control studies are inconclusive (West et al, 1991; Platz et al, 2002; Vinceti et al, 2007; Chen et al, 2009).

No prospective studies have examined the relationship between dietary exposure to cadmium and prostate cancer risk. Herein we assessed the relation between cadmium exposure via food and prostate cancer incidence and mortality in a large population-based prospective cohort of men.

\section{SUBJECTS AND METHODS}

\section{Study population}

The Cohort of Swedish Men was established in 1997-1998, when all eligible men aged 45-79 years and residing in Västmanland and Örebro counties in Central Sweden received an invitation to participate in the study along with a self-administrated questionnaire, including almost 350 items on diet and other lifestyle factors. Of those invited, 48645 returned a complete questionnaire (response rate $49 \%$ ). This large population-based cohort is 
representative of Swedish males aged 45-79 years, in terms of age distribution, educational level and prevalence of overweight (Norman et al, 2002). Incidence rates in 1998 per 100000 men are almost the same: for example, the incidence rate among men aged 65-69 years was 603 in our cohort and 595 in the entire Sweden (NBHW, 2000; Orsini et al, 2009). Ethical approval for the study was granted by the Regional Ethical Review Board in Stockholm, Sweden, and return of the completed questionnaire was considered to imply informed consent.

We excluded from the baseline population those men with incorrect or incomplete national registration numbers and those who were diagnosed with cancer (not including non-melanoma skin cancer) or moved out of the county prior to baseline, based on computerised linkage of the cohort to the National Cancer Registry and the Population Registry. We also excluded those who reported an implausible energy intake $( \pm 3$ s.d. of mean log-transformed energy, $n=567)$. We further excluded from the baseline population those diagnosed with diabetes prior to $1998(n=4250$, based on self-reports and the National Hospital Discharge Registry data), as diabetes is associated with decreased risk of prostate cancer and the dietary advice given to diabetics is likely to lead to an increased exposure to cadmium (Giovannucci and Michaud, 2007). Thus, the analytical cohort for the primary analysis consisted of 41089 men.

\section{Assessment of diet and covariates}

Dietary intake was assessed at baseline using a 96-item food frequency questionnaire (FFQ). Participants reported their average frequency of consumption of each food item during the previous year. The frequency of consumption was reported according to eight predefined categories, ranging from never/seldom to more than three times per day. The consumption of bread and dairy products was assessed using open-ended questions. The validity of the FFQ has been assessed in a random population-based sample of 248 men aged between $40-74$ years living in the study area, which completed the FFQ and 14 repeated 24 -h recalls during a 1 -year period. For macronutrients, the mean Spearman's rank correlation coefficient was 0.65 , and for the micronutrients calcium and selenium, the coefficients were 0.77 and 0.72 , respectively (Messerer et al, 2004).

The average daily dietary cadmium exposure was calculated by multiplying the consumption frequencies from the FFQ by age-specific portion sizes and the average cadmium content in each food item. The data on cadmium concentrations in foods were mainly provided by the Swedish National Food Agency. We used the average cadmium content in each food item because there is no detected geographic variation of cadmium content in foods across Sweden (Jorhem and Sundstrom, 1993), and most foods are distributed throughout Sweden by a small number of wholesale companies. Thus, the cadmium concentrations in food used in the database in this study are expected to represent the actual exposure levels in the area. Exposures from other sources, such as drinking water and air, are low and were ignored (Vahter et al, 1991; Olsson et al, 2002). We obtained questionnaire data on family history of prostate cancer, education, height (at age 20), weight, waist circumference, smoking habits and physical activity. Based on the reported weight and height, we calculated the body mass index (BMI) as weight $(\mathrm{kg})$ divided by height ${ }^{2}\left(\mathrm{~m}^{2}\right)$. The time spent per day at specific activities was multiplied by its typical energy expenditure requirements (expressed in metabolic equivalents (METs) and summarised in MET hours per day (Norman et al, 2001)).

\section{Ascertainment of prostate cancer cases}

Incident cases of prostate cancer occurring between 1 January 1998 and 31 December 2009 were identified by linkage of the cohort to the National Cancer Registry, close to $100 \%$ complete
(Mattsson and Wallgren, 1984). Information on tumour (T)-node $(\mathrm{N})$-metastasis (M) stage, Gleason grade and PSA was ascertained through medical records and the Swedish Prostate Cancer Quality Registry. Incident cases were classified by subtype as localised ( $\mathrm{T}$ stage $<3$, Gleason grade $\leqslant 6$ and PSA $<10$ ) or advanced ( $\mathrm{T}$ stage $=4, \mathrm{~N}=1, \mathrm{M}=1$, Gleason grade $>7$ or PSA $>100$ ). Because of this specific classification (not including Gleason grade 7 ), only $55 \%$ of the prostate cancer cases were classified as either localised or advanced. Information on prostate cancer death was ascertained through linkage to the Swedish Register of Death Causes at the National Board of Health and Welfare. Classification of deaths was based on the International Classification of Diseases (ICD-10, code 61 for prostate cancer).

\section{Statistical analysis}

Follow-up was censored at the date of invasive prostate cancer diagnosis, death or 31 December 2009, whichever occurred first. In the case of fatal tumours, end of follow-up was 31 December 2008. We used Cox proportional hazards regression models with attained age (1-year units) as the time scale to estimate rate ratios (RRs) with $95 \%$ confidence intervals (CIs) of prostate cancer by tertiles of dietary cadmium exposure. Cadmium intake values were adjusted to the mean energy intake in the cohort $(2600 \mathrm{kcal}$ per day) using the residual-regression method (Willett and Stampfer, 1986). In the multivariable analysis, we adjusted for attained age, family history of prostate cancer (yes, no), years of education $(\geqslant 12,<12$ years $)$, BMI $\left(18.5-<25,25-<30\right.$ and $\left.\geqslant 30 \mathrm{~kg} \mathrm{~m}^{-2}\right)$, waist circumference $(<94,94-<102$ and $\geqslant 102 \mathrm{~cm})($ WHO, 2000), MET hours per day (quartiles), smoking status (ever, never), total energy intake (kcal cont.) and alcohol consumption $(<0.1$, $0.1-<5,5-<10,10-<15$ and $\geqslant 15 \mathrm{~g}$ per day). Because dietary intake of selenium, lycopene and calcium has been evaluated as probable protective factors for the risk of prostate cancer (World Cancer Research Fund (WCRF), 2007), we also included tertiles of these variables in the multivariable analysis. The Schoenfeld's residual test indicated no violation of the proportional hazard assumption (Grambsch and Therneau, 1994). We formally tested for heterogeneity of prostate cancer subtypes (localised, advanced and fatal) using the Cochran's Q-test. Linear trends across categories were tested using the median cadmium values within categories as a continuous variable. We performed stratified analysis by waist circumference $(<94$ or $\geqslant 94 \mathrm{~cm})$ in prostate cancer subtypes because associations may differ between lean and obese men (Calle and Kaaks, 2004; Discacciati et al, 2011). All reported $P$-values were two-sided and values $<0.05$ were considered statistically significant. Missing values-treated as a separate 'missing category' in the models-were generally very few $(<2 \%)$ with the exception of waist circumference and physical activity $(\sim 20 \%)$. To evaluate a potential effect of missing values on the observed results, we used multiple imputation using chained equations with 30 imputated data sets (White et al, 2011). Statistical analysis was performed with Stata, version 11 (StataCorp., College Station, TX, USA).

\section{RESULTS}

The mean estimated energy-adjusted cadmium exposure in the 41089 study participants at baseline was $19 \mu \mathrm{g}$ per day \pm s.d. 3.7, and only $4 \%$ exceeded the tolerable weekly intake $\left(2.5 \mu \mathrm{g} \mathrm{kg}^{-1}\right.$ of body weight) set by the European Food Safety Authority (EFSA, 2009). The major contributors to the dietary cadmium exposure were bread $(33 \%)$, potatoes $(18 \%)$, other cereals than bread $(15 \%)$ and vegetables, including root vegetables (14\%), as compared with offal products, meat and shellfish $(2 \%, 4 \%$ and $1 \%$, respectively) (Figure 1). Age-standardised characteristics by category of dietary cadmium exposure are shown in Table 1. Men in the highest tertile 


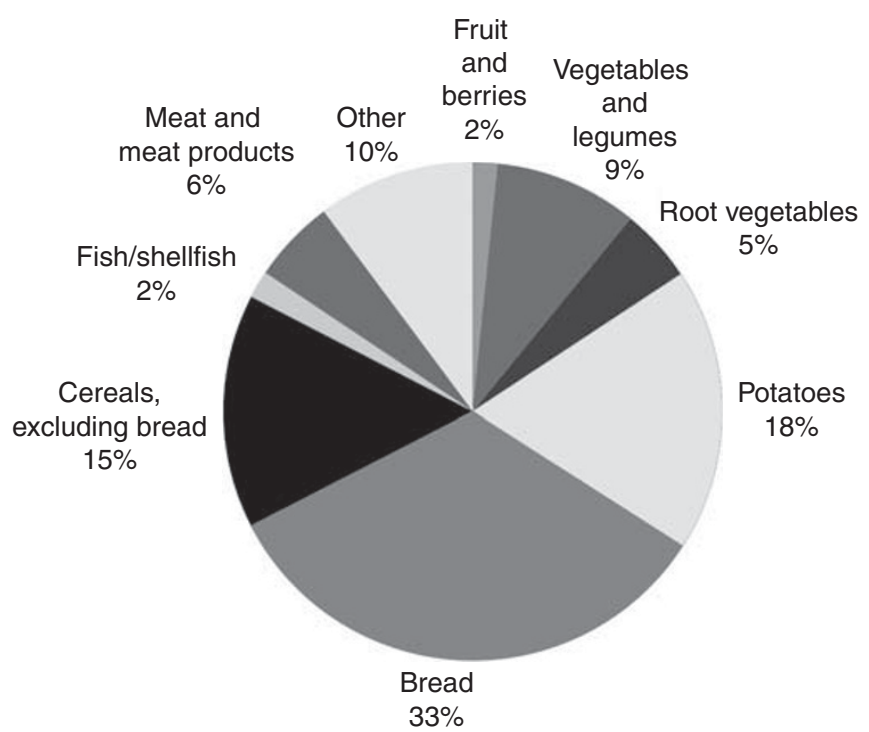

Figure I Major sources to dietary cadmium exposure within the Cohort of Swedish Men.

Table I Age-standardised baseline characteristics by categories of dietary cadmium exposure in 4I 089 men, aged 45-79 years, the Cohort of Swedish Men

\begin{tabular}{|c|c|c|c|}
\hline & \multicolumn{3}{|c|}{$\begin{array}{l}\text { Tertiles of dietary cadmium } \\
\text { exposure, } \mu \mathrm{g} \text { per day }\end{array}$} \\
\hline & $<17$ & $17-20$ & $>\mathbf{2 0}$ \\
\hline \multicolumn{4}{|l|}{ Characteristics $^{\mathrm{a}}$} \\
\hline Mean cadmium ( $\mu \mathrm{g}$ per day) & 15 & 19 & 23 \\
\hline Age (years) & 60 & 59 & 60 \\
\hline Family history of prostate cancer (\%) & 9 & 10 & 9 \\
\hline$\geqslant 12$ years of education $(\%)$ & 16 & 17 & 18 \\
\hline Weight (mean, kg) & 81 & 81 & 80 \\
\hline Body mass index (mean, $\mathrm{kg} \mathrm{m}^{-2}$ ) & 26 & 26 & 26 \\
\hline Waist circumference $(<94 \mathrm{~cm}, \%)$ & 32 & 35 & 37 \\
\hline MET (hours per day) & 41 & 41 & 42 \\
\hline \multicolumn{4}{|l|}{ Smoking status (\%) } \\
\hline Ever smoker & 67 & 61 & 59 \\
\hline Never smoker & 33 & 39 & 41 \\
\hline Total energy intake (mean, kcal) & 2690 & 2690 & 2666 \\
\hline Alcohol intake (mean, g per day) & 17 & 14 & 12 \\
\hline Selenium (mean, $\mu \mathrm{g}$ per day) & 38 & 39 & 40 \\
\hline Lycopene (mean, $\mu \mathrm{g}$ per day) & 2056 & 2442 & 2683 \\
\hline Calcium (mean, mg per day) & 1627 & |44| & 1309 \\
\hline
\end{tabular}

Abbreviation: $M E T$ = metabolic equivalent. ${ }^{a}$ All factors, except age were directly standardised to the age distribution of the study participants. ${ }^{b}$ Energy adjusted to $2600 \mathrm{kcal}$

of dietary cadmium exposure were more likely to never have smoked and to have a lower intake of alcohol and calcium, but a higher intake of lycopene, compared with men in the lowest tertile.

During a mean follow-up of 10.8 years (443599 person-years), we ascertained 3085 incident cases of prostate cancer (894 localised, 794 advanced and 326 fatal cases). Age and multivariable-adjusted RRs for prostate cancer incidence of overall, localised, advanced and fatal prostate cancers according to dietary cadmium exposure are presented in Table 2. Dietary cadmium exposure was, after multivariable-adjustment, associated with a statistically significant RR of 1.13 (95\% CI: 1.03-1.24) of overall prostate cancer, comparing the highest tertile with the lowest (Table 2). Multiple imputation of missing data did not change the results substantially; multivariable-adjusted RR 1.15 (95\% CI: 1.05-1.26) for all tumours comparing the highest tertile of dietary cadmium with the lowest. A similar risk estimate (RR 1.13; 95\% CI: 1.01-1.26) was also observed when substituting the dietary cadmium exposure by the consumption of foods rich in cadmium (all cereals and vegetables), comparing the highest tertile with the lowest.

In subtypes of prostate cancer tumours, the RR was $1.29(95 \%$ CI: 1.08-1.53) for localised cases, 1.05 (95\% CI: 0.87-1.25) for advanced cases and 1.14 (95\% CI: 0.86-1.51) for fatal cases. No statistically significant difference was observed in the multivariable-adjusted risk estimates between localised, advanced and fatal tumours $\left(P_{\text {heterogeneity }}=0.27\right)$. We did not observe any support for a modification by zinc in the multivariable-adjusted models $\left(P_{\text {interaction }}=0.32\right.$ for overall prostate cancer, 0.57 for localised, 0.76 for advanced and 0.69 for fatal prostate cancer).

We explored if central obesity or smoking status modified the risk of prostate cancer. In stratified analyses, the RR for localised tumours was 1.55 (95\% CI: $\left.1.16-2.08 ; P_{\text {interaction }}=0.73\right)$ among men with a waist circumference $<94 \mathrm{~cm}$ and 1.45 (95\% CI: $1.15-$ 1.83 ; $P_{\text {interaction }}=0.30$ ) among men reporting to have ever smoked, comparing the highest dietary cadmium exposure tertile with the lowest (Table 3 ).

\section{DISCUSSION}

In this large population-based prospective cohort of men, dietary cadmium exposure was associated with a slightly increased risk of total prostate cancer tumours. For localised prostate cancer tumours, the risk tended to be more pronounced among lean men and among those who reported smoking.

The estimated average dietary cadmium exposure in the studied population of men was in a similar range as that observed both in the United States and elsewhere in Europe (MacIntosh et al, 1996; Thomas et al, 1999; Larsen et al, 2002; Llobet et al, 2003; Rose et al, 2010). Four studies (West et al, 1991; Platz et al, 2002; Vinceti et al, 2007; Chen et al, 2009) have assessed the association between cadmium exposure present in the general non-occupationally exposed populations and prostate cancer risk, with inconsistent results. Only one of them assessed the cadmium exposure through diet (West et al, 1991): In a population-based case-control study in Utah, comparing extreme quartiles, an increase in prostate cancer risk for all tumours (OR 1.8; 95\% CI: 1.1-3.1) was observed in elderly men (aged 68-74 years), but not in younger (OR 1.1; 95\% CI: 0.7-1.9). In an Italian hospital-based case-control study, a 4.7-fold increased risk (95\% CI: $1.3-17.5$ ) of prostate cancer was observed, comparing the highest quartile of toenail cadmium with the lowest (Vinceti et al, 2007). Our results are in line with those observations. However, no difference was observed in blood cadmium between Taiwanese hospital-based cases and controls, although cases had lower urinary cadmium (Chen et al, 2009). In an American nested case-control study, no association was observed between toenail cadmium and the risk of prostate cancer (Platz et al, 2002). The validity of toenail cadmium concentration as a marker of cadmium body burden is uncertain as the factors influencing the deposition of cadmium in toenails and the time-course of deposition is unknown (Platz et al, 2002).

Cadmium was shown to cause prostate cancer in rodents (Goyer et al, 2004) and induces malignant transformation of human prostate epithelial cells (Achanzar et al, 2001; Nakamura et al, 2002). The prostate is one of the target organs for bioaccumulation of cadmium (Elinder, 1985; Lindegaard et al, 1990) and higher accumulation have been observed in prostate cancer patients (Brys et al, 1997). The mechanisms involved in cadmium carcinogenesis are unclear, but are proposed to occur via indirect genotoxic mechanisms, such as oxidative stress, inhibition 
Table 2 Rate ratios (RRs) and 95\% confidence intervals (Cls) of total prostate cancer and its subtypes by tertiles of dietary cadmium exposure, the Cohort of Swedish Men 1998-2009

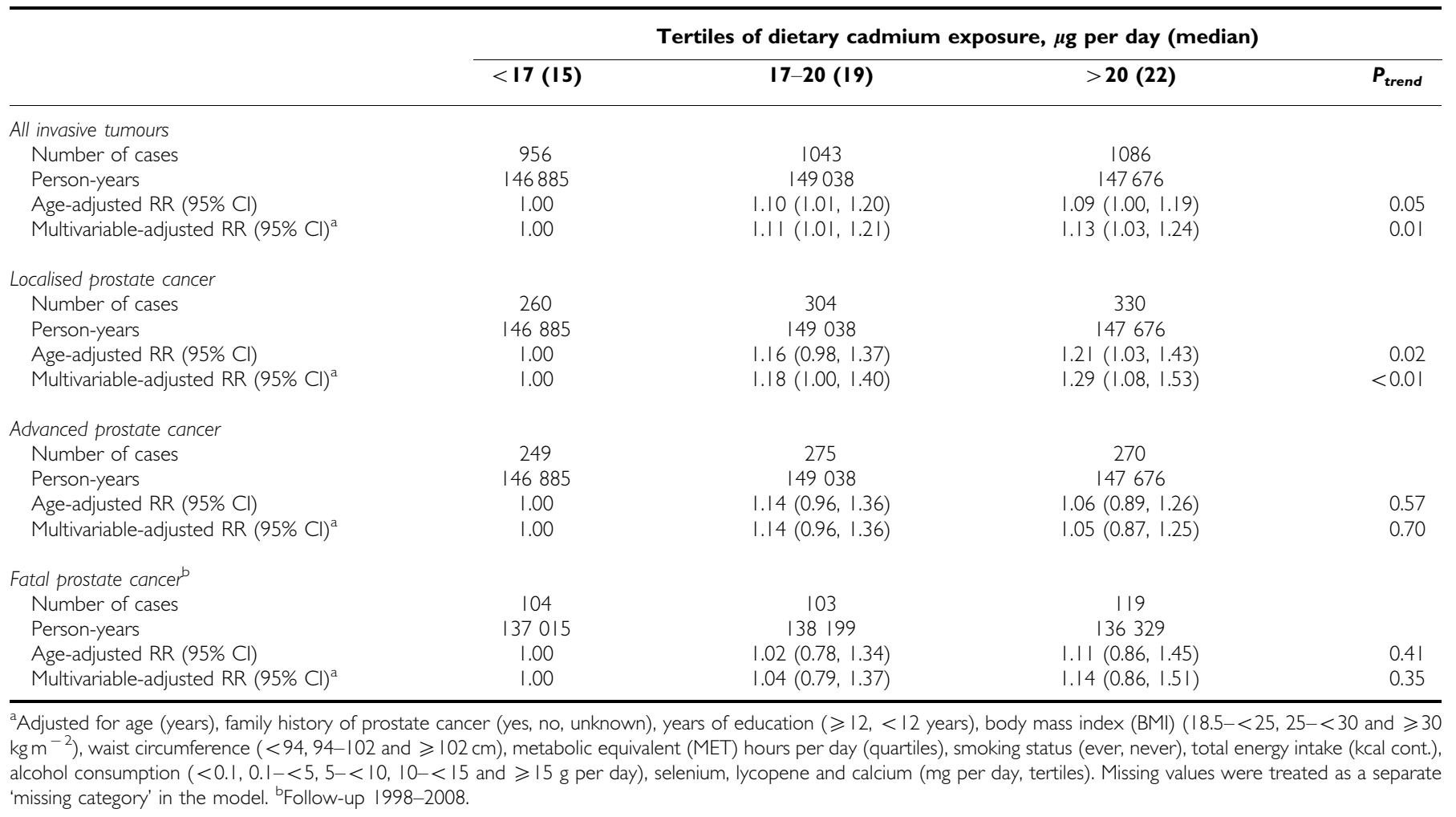

Table 3 Multivariable-adjusted rate ratios (RRs) and 95\% confidence intervals (Cls) of prostate cancer subtypes by tertiles of dietary cadmium exposure stratified by waist circumference and smoking status, the Cohort of Swedish Men 1998-2009

\begin{tabular}{|c|c|c|c|c|c|c|c|}
\hline & \multicolumn{7}{|c|}{ Tertiles of dietary cadmium exposure, $\mu \mathrm{g}$ per day (median) } \\
\hline & \multicolumn{2}{|l|}{$<17$ (15) } & \multicolumn{2}{|c|}{$17-20(19)$} & \multicolumn{2}{|c|}{$>20(22)$} & $P_{\text {trend }}$ \\
\hline \multicolumn{8}{|c|}{ Localised prostate cancer } \\
\hline \multicolumn{8}{|c|}{ Waist circumference ${ }^{a}$} \\
\hline$<94 \mathrm{~cm}$ & 81 & 1.00 & 118 & $1.47(1.10,1.96)$ & 130 & $1.55(1.16,2.08)$ & $<0.01$ \\
\hline Never & 112 & 1.00 & 124 & $1.00(0.77,1.29)$ & 140 & $1.09(0.83,1.42)$ & 0.52 \\
\hline Ever & 143 & 1.00 & 174 & $1.31(1.05,1.65)$ & 184 & $1.45(1.15,1.83)$ & $<0.01$ \\
\hline \multicolumn{8}{|c|}{ Advanced prostate cancer } \\
\hline \multicolumn{8}{|c|}{ Waist circumference ${ }^{\mathrm{a}}$} \\
\hline$<94 \mathrm{~cm}$ & 82 & 1.00 & 89 & $1.05(0.78,1.43)$ & 113 & $1.18(0.88,1.60)$ & 0.26 \\
\hline$\geqslant 94 \mathrm{~cm}$ & 125 & 1.00 & 136 & $1.11(0.87,1.42)$ & 120 & $0.97(0.75,1.27)$ & 0.81 \\
\hline \multicolumn{8}{|c|}{ Fatal prostate cancer ${ }^{c}$} \\
\hline \multicolumn{8}{|c|}{ Waist circumference ${ }^{a}$} \\
\hline$<94 \mathrm{~cm}$ & 32 & 1.00 & 29 & $0.88(0.53,1.46)$ & 40 & $1.12(0.68,1.82)$ & 0.61 \\
\hline$\geqslant 94 \mathrm{~cm}$ & 51 & 1.00 & 59 & $1.20(0.82,1.75)$ & 61 & $1.23(0.83,1.82)$ & 0.33 \\
\hline \multicolumn{8}{|c|}{ Smoking status ${ }^{b}$} \\
\hline Never & 35 & 1.00 & 42 & $1.14(0.72,1.80)$ & 45 & $1.09(0.68,1.75)$ & 0.74 \\
\hline Ever & 66 & 1.00 & 60 & $1.03(0.72,1.46)$ & 72 & $1.21(0.85,1.73)$ & 0.28 \\
\hline
\end{tabular}


of DNA repair, stimulation of cell proliferation, blockage of apoptosis or through epigenetic mechanisms (Hartwig, 2010). Because oestrogen receptors are found in the prostate, and cadmium is suggested to have oestrogenic properties (Johnson et al, 2003), direct receptor-mediated effects of oestrogens on the prostate are plausible. There is experimental evidence to support a role of too much or untimely exposure to estrogens in the development of prostate cancer (Härkönen and Mäkelä, 2004). In human prostate epithelial cells, cadmium increased proliferation through an oestrogen receptor-dependent mechanism and promoted androgen independence of the tumours (BenbrahimTallaa et al, 2007). Of interest is to note that we have previously observed, in a large prospective cohort of women, statistically significant positive associations between dietary cadmium exposure and risk of endometrial (Åkesson et al, 2008) and breast cancer (Julin et al, 2012), but not ovarian cancer (Julin et al, 2011). In the present study, there were indications of stronger associations with high dietary cadmium exposure among lean men and ever smokers. We can only speculate that endogenous sexhormone profiles differ, depending on the amount of body fat (Calle and Kaaks, 2004), and that this may influence any potential effect of cadmium on prostate cancer risk.

To date, no single dietary factor has been shown to be conclusively associated to the risk of prostate cancer. Fibre-rich foods and vegetables - foods in general considered healthy, but at the same time being the major sources to dietary cadmium exposure-have, however, been hypothesised to have protective effects. In the present study, we observed similar increased risk for dietary cadmium as for the major food sources of the metal, similar to the slightly positive association (RR 1.13; 95\% CI: 1.03-1.24) reported in the Health Professionals follow-up study between dietary intake of whole grains and total prostate cancer (Nimptsch et al, 2011). Results from a Danish prospective study of middle-aged men did not observe any association between intakes of total or specific whole-grain products and risk of prostate cancer (Egeberg et al, 2011).

This study has several limitations. Most important is that whether the estimated intake of cadmium provides a valid measure of exposure. Dietary assessments are always subjected to misclassification due to the difficulty of reporting diet correctly and, although the used mean concentrations of cadmium in specific foods in some cases were based on several hundred measurements, we may not account for all the variability in cadmium content in the reported food. We did not have the possibility to assess the relationship between the FFQ-based

\section{REFERENCES}

Achanzar WE, Diwan BA, Liu J, Quader ST, Webber MM, Waalkes MP (2001) Cadmium-induced malignant transformation of human prostate epithelial cells. Cancer Res 61(2): 455-458

Åkesson A, Julin B, Wolk A (2008) Long-term dietary cadmium intake and postmenopausal endometrial cancer incidence: a population-based prospective cohort study. Cancer Res 68(15): 6435-6441

Benbrahim-Tallaa L, Liu J, Webber MM, Waalkes MP (2007) Estrogen signaling and disruption of androgen metabolism in acquired androgenindependence during cadmium carcinogenesis in human prostate epithelial cells. Prostate 67(2): 135-145

Brys M, Nawrocka AD, Miekos E, Zydek C, Foksinski M, Barecki A, Krajewska WM (1997) Zinc and cadmium analysis in human prostate neoplasms. Biol Trace Elem Res 59(1-3): 145-152

Calle EE, Kaaks R (2004) Overweight, obesity and cancer: epidemiological evidence and proposed mechanisms. Nat Rev Cancer 4(8): 579-591

Chen YC, Pu YS, Wu HC, Wu TT, Lai MK, Yang CY, Sung FC (2009) Cadmium burden and the risk and phenotype of prostate cancer. $B M C$ Cancer 9: 429

Discacciati A, Orsini N, Andersson SO, Andren O, Johansson JE, Wolk A (2011) Body mass index in early and middle-late adulthood and risk of cadmium-exposure estimates and a biomarker in this cohort of men. However, among women of approximately the same age and from the same geographical region as the men, we observed an $r=0.2$ between FFQ-estimated dietary cadmium exposure and urinary cadmium concentrations, indicating misclassification of the exposure. Because of the prospective design of this study, the misclassification is most likely non-differential. Accounting for this misclassification suggested a likely underestimation of the true exposure-risk association (Julin et al, 2012). Our study was observational and may therefore be subjected to residual confounding.

The major strengths of this study include its population-based and prospective study design, which eliminates recall and selection bias. Although the response rate was $49 \%$, the incidence rate of prostate cancer in the cohort was almost the same as in the whole male population of Sweden, and the cohort participants were considered representative in terms of age distribution, educational level and prevalence of overweight (Norman et al, 2002). Further, we were able to ascertain a relatively large number of cases, and the case ascertainment was highly complete, thanks to matching of the cohort with the national and regional cancer registers. We also assessed the association in subtypes of prostate cancer based on their aggressiveness. As information on exposure was collected prospectively, any non-differential misclassification of dietary cadmium would probably bias our observed relative risks toward the null rather than exaggerate the true association between dietary cadmium exposure and prostate cancer.

In conclusion, our findings based on prospective, populationbased data provide support that dietary cadmium exposure has a potential harmful role in prostate cancer development.

\section{ACKNOWLEDGEMENTS}

We thank L Jorhem, J Engman and B Sundström from the Swedish National Food Agency for providing food-cadmium data. This work was supported by the Swedish Research Council for Environment, Agricultural Sciences and Spatial Planning (to A and the Swedish Research Council/Medicine and Infrastructures (to AW).

\section{Conflict of interest}

The authors declare no conflict of interest. 
Härkönen PL, Mäkelä SI (2004) Role of estrogens in development of prostate cancer. J Steroid Biochem Mol Biol 92(4): 297-305

IARC (2011) A review of human carcinogens-part C: metals, arsenic, dusts, and fibres. Lancet Oncol 10(5): 453-454

Järup L, Åkesson A (2009) Current status of cadmium as an environmental health problem. Toxicol Appl Pharmacol 238(3): 201-208

Jemal A, Bray F, Center MM, Ferlay J, Ward E, Forman D (2011) Global cancer statistics. CA Cancer J Clin 61(2): 69-90

Johnson MD, Kenney N, Stoica A, Hilakivi-Clarke L, Singh B, Chepko G, Clarke R, Sholler PF, Lirio AA, Foss C, Reiter R, Trock B, Paik S, Martin $\mathrm{MB}$ (2003) Cadmium mimics the in vivo effects of estrogen in the uterus and mammary gland. Nat Med 9(8): 1081-1084

Jorhem L, Sundstrom B (1993) Levels of lead, cadmium, zinc, copper, nickel, chromium, manganese, and cobalt in foods on the Swedish market, 1983-1990. J Food Compos Anal 6: 223-241

Julin B, Wolk A, Akesson A (2011) Dietary cadmium exposure and risk of epithelial ovarian cancer in a prospective cohort of Swedish women Br J Cancer 105(3): 441-444

Julin B, Wolk A, Bergkvist L, Bottai M, Åkesson A (2012) Dietary cadmium exposure and risk of postmenopausal breast cancer: a population-based prospective cohort study. Cancer Res 72: 1459-1466

Kippler M, Goessler W, Nermell B, Ekstrom EC, Lonnerdal B, El Arifeen S, Vahter M (2009) Factors influencing intestinal cadmium uptake in pregnant Bangladeshi women-a prospective cohort study. Environ Res 109(7): 914-921

Larsen EH, Andersen NL, Moller A, Petersen A, Mortensen GK, Petersen J (2002) Monitoring the content and intake of trace elements from food in Denmark. Food Addit Contam 19(1): 33-46

Lindegaard PM, Hansen SO, Christensen JE, Andersen BB, Andersen O (1990) The distribution of cadmium within the human prostate. Biol Trace Elem Res 25(2): 97-104

Llobet JM, Falco G, Casas C, Teixido A, Domingo JL (2003) Concentrations of arsenic, cadmium, mercury, and lead in common foods and estimated daily intake by children, adolescents, adults, and seniors of Catalonia, Spain. J Agric Food Chem 51(3): 838-842

MacIntosh DL, Spengler JD, Ozkaynak H, Tsai L, Ryan PB (1996) Dietary exposures to selected metals and pesticides. Environ Health Perspect 104(2): 202-209

Mattsson B, Wallgren A (1984) Completeness of the Swedish Cancer Register. Non-notified cancer cases recorded on death certificates in 1978. Acta Radiol Oncol 23: 305-313

Messerer M, Johansson SE, Wolk A (2004) The validity of questionnairebased micronutrient intake estimates is increased by including dietary supplement use in Swedish men. J Nutr 134(7): 1800-1805

Nakamura K, Yasunaga Y, Ko D, Xu LL, Moul JW, Peehl DM, Srivastava S, Rhim JS (2002) Cadmium-induced neoplastic transformation of human prostate epithelial cells. Int J Oncol 20(3): 543-547

NBHW (2000) Cancer Incidence in Sweden 1998. The National Board of Health and Wellfare, Centre of Epidemiology: Stockholm. Report no. 91-7201-450-4

Nimptsch K, Kenfield S, Jensen MK, Stampfer MJ, Franz M, Sampson L, Brand-Miller JC, Willett WC, Giovannucci E (2011) Dietary glycemic index, glycemic load, insulin index, fiber and whole-grain intake in relation to risk of prostate cancer. Cancer Causes Control 22(1): 51-61

Norman A, Bellocco R, Bergstrom A, Wolk A (2001) Validity and reproducibility of self-reported total physical activity-differences by relative weight. Int J Obes Relat Metab Disord 25(5): 682-688

Norman A, Bellocco R, Vaida F, Wolk A (2002) Total physical activity in relation to age, body mass, health and other factors in a cohort of Swedish men. Int J Obes Relat Metab Disord 26(5): 670-675
Olsson IM, Bensryd I, Lundh T, Ottosson H, Skerfving S, Oskarsson A (2002) Cadmium in blood and urine-impact of sex, age, dietary intake, iron status, and former smoking-association of renal effects. Environ Health Perspect 110(12): 1185-1190

Orsini N, Bellocco R, Bottai M, Pagano M, Andersson SO, Johansson JE, Giovannucci E, Wolk A (2009) A prospective study of lifetime physical activity and prostate cancer incidence and mortality. Br J Cancer 101(11): 1932-1938

Pan J, Plant JA, Voulvoulis N, Oates CJ, Ihlenfeld C (2010) Cadmium levels in Europe: implications for human health. Environ Geochem Health 32(1): 1-12

Patel AV, Cheng I, Canzian F, Le Marchand L, Thun MJ, Berg CD, Buring J, Calle EE, Chanock S, Clavel-Chapelon F, Cox DG, Dorronsoro M, Dossus L, Haiman CA, Hankinson SE, Henderson BE, Hoover R, Hunter DJ, Kaaks R, Kolonel LN, Kraft P, Linseisen J, Lund E, Manjer J, McCarty C, Peeters PH, Pike MC, Pollak M, Riboli E, Stram DO, Tjonneland A, Travis RC, Trichopoulos D, Tumino R, Yeager M, Ziegler RG, Feigelson HS (2008) IGF-1, IGFBP-1, and IGFBP-3 polymorphisms predict circulating IGF levels but not breast cancer risk: findings from the Breast and Prostate Cancer Cohort Consortium (BPC3). PLoS One 3(7): e2578

Platz EA, Helzlsouer KJ, Hoffman SC, Morris JS, Baskett CK, Comstock GW (2002) Prediagnostic toenail cadmium and zinc and subsequent prostate cancer risk. Prostate 52(4): 288-296

Rose M, Baxter M, Brereton N, Baskaran C (2010) Dietary exposure to metals and other elements in the 2006 UK Total Diet Study and some trends over the last 30 years. Food Addit Contam Part A Chem Anal Control Expo Risk Assess 27(10): 1380-1404

Sahmoun AE, Case LD, Jackson SA, Schwartz GG (2005) Cadmium and prostate cancer: a critical epidemiologic analysis. Cancer Invest 23(3): 256-263

Thomas KW, Pellizzari ED, Berry MR (1999) Population-based dietary intakes and tap water concentrations for selected elements in the EPA region V National Human Exposure Assessment Survey (NHEXAS). $J$ Expo Anal Environ Epidemiol 9(5): 402-413

Vahter M, Berglund M, Slorach S, Friberg L, Saric M, Zheng XQ, Fujita M (1991) Methods for integrated exposure monitoring of lead and cadmium. Environ Res 56(1): 78-89

van Wijngaarden E, Singer EA, Palapattu GS (2008) Prostate-specific antigen levels in relation to cadmium exposure and zinc intake: results from the 2001-2002 National Health and Nutrition Examination Survey. Prostate 68(2): 122-128

Vinceti M, Venturelli M, Sighinolfi C, Trerotoli P, Bonvicini F, Ferrari A, Bianchi G, Serio G, Bergomi M, Vivoli G (2007) Case-control study of toenail cadmium and prostate cancer risk in Italy. Sci Total Environ 373(1): 77-81

Waalkes MP (2003) Cadmium carcinogenesis. Mutat Res 533(1-2): 107-120

West DW, Slattery ML, Robison LM, French TK, Mahoney AW (1991) Adult dietary intake and prostate cancer risk in Utah: a case-control study with special emphasis on aggressive tumors. Cancer Causes Control 2(2): 85-94

White IR, Royston P, Wood AM (2011) Multiple imputation using chained equations: Issues and guidance for practice. Stat Med 30(4): 377-399

WHO (2000) Obesity: Preventing and Managing the Global Epidemic: Report on a WHO Consultation (WHO Technical Report Series 894). World Health Organization: Geneva, Switzerland

Willett W, Stampfer MJ (1986) Total energy intake: implications for epidemiologic analyses. Am J Epidemiol 124(1): 17-27

World Cancer Research Fund (WCRF) (2007) Food, Nutrition and the Prevention of Cancer: A Global Perspective. World Cancer Research Fund/American Institute for Cancer Research: Washington

This work is published under the standard license to publish agreement. After 12 months the work will become freely available and the license terms will switch to a Creative Commons Attribution-NonCommercial-Share Alike 3.0 Unported License. 